\title{
Transient Simulation of the Power Block in a Parabolic Trough Power Plant
}

\author{
Heiko Schenk ${ }^{1}$ Jürgen Dersch ${ }^{2}$ Tobias Hirsch ${ }^{3}$ Thomas Polklas ${ }^{4}$ \\ ${ }^{1}$ German Aerospace Center (DLR), Institut of Solar Energy, Germany, \\ \{Heiko.Schenk, Juergen. Dersch ${ }^{2}$, Tobias.Hirsch ${ }^{3}$ @dlr. de \\ ${ }^{4}$ MAN Diesel \& Turbo SE, Process Industry/Engineering Steam Turbines, Thomas . Polklas @man . eu
}

\begin{abstract}
In the field of concentrated solar power (CSP) plants, parabolic trough systems with thermal oil as heat transfer fluid represent the technically and economically most mature technology. Due to storage systems these plants produce electricity on demand. However, a considerable portion of the annually collected thermal energy is consumed for the start-up procedure. In fact, after shut-down periods thermal masses must be reheated and additionally further energy losses due to imperfect start-up procedures occur. The present work has been carried out within the TURIKON project. The main goal is to evaluate and to optimize the transient behavior, namely the start-up of parabolic trough plants with thermal oil. For this purpose, a dynamic model was developed. An internal DLR solar library was used for the modelling of the solar field while the power block is modelled with the publically available ThermoPower library where some components had to be adapted for the needs of CSP plants. In the present publication first results are shown in order to demonstrate the capabilities of the plant model. The dynamic behavior of the power plant during normal operating mode and during a warm and a hot start-up procedure is evaluated and the warm start-up procedure energetically optimized.
\end{abstract}

Keywords: transient power block simulation, parabolic trough, concentrated solar power

\section{Introduction}

With the penetration of fluctuating renewable energy resources, such as wind and photovoltaic, dispatchability gets more into focus. Concentrated solar power plants offer the possibility to produce electricity on demand due to their cost-effective thermal storage systems. In the sector of point focus systems solar tower power plants aim at high process temperatures, using molten salt as heat transfer fluid or gas in order to operate high temperature gas turbines. In the sector of parabolic trough plants, the aim is to develop high-temperature processes with direct steam generation or molten salt as heat transfer fluid. However, parabolic trough power plants with thermal oil represent the state-of-the-art. With more than 2 $\mathrm{GW}_{\mathrm{el}}$ installed in Spain (Protermo Solar, 2015), these plants are the economically most mature technology amongst all CSP system. In these plants thermal oil is heated in the solar field and thermal power is transferred to a conventional water-steam cycle, where electricity is produced. Several plants are equipped with a two-tank molten salt storage system which is connected with the oil circuit with a heat exchanger. The storage system allows decoupling the electricity production from the solar energy input. However, the process parameters of these plants are limited due to the decomposition temperature of the thermal oil of $400{ }^{\circ} \mathrm{C}$.

The modelling and simulation work presented in this paper has been carried out within the TURIKON project. In this project DLR, MAN Diesel \& Turbo and the University of Duisburg Essen work jointly together. Among other goals, the aim is to examine and to optimize the transient operation and the start-up procedure of solar field and power block. In fact, the thermodynamic behavior of both subsystems is characterized by their thermal inertia that stems from fluid and steel masses. These thermal masses have a smoothing effect on the electricity production during cloudy periods. After plant shut-down, fluid and steel masses cool down individually. During the start-up process they have to be heated-up. The energy consumption of the start-up processes can account for 5 to $10 \%$ of the annual heat production, depending on the plant's configuration and meteorological conditions. From here, it becomes clear, that the startup procedure presents a considerable energetic optimization potential

In previous works on the start-up procedure of parabolic trough plants with direct steam generation, (Hirsch et al, 2006), and with thermal oil, (Hirsch et al, 2012), a DLR-internal Dymola library was used for the modelling of the solar field. The present publication focuses on the modelling of the power block, for which the freely available ThermoPower library was used with some adaptions and was coupled with the DLRinternal solar library. 


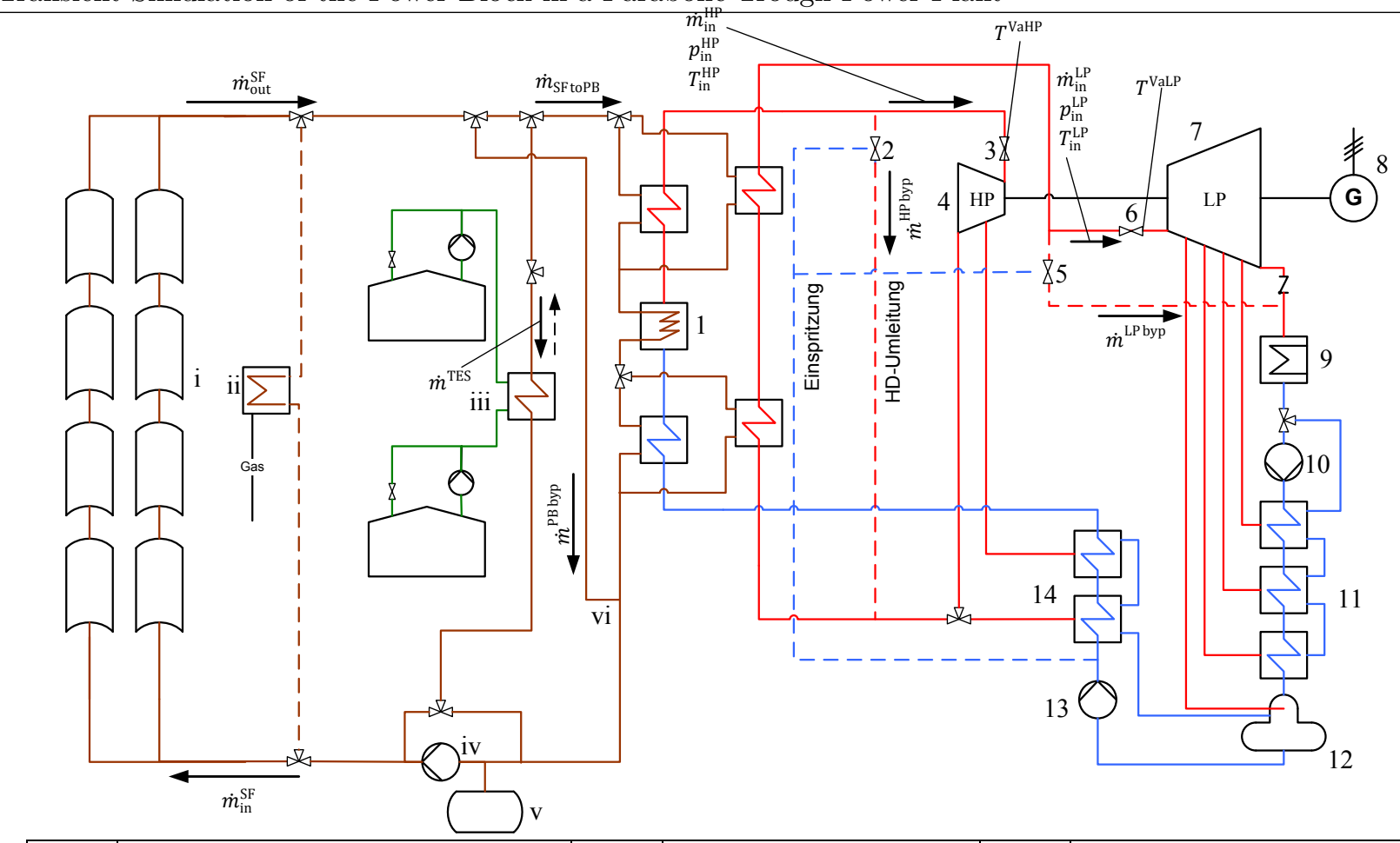

\begin{tabular}{|c|l|c|l|c|l|}
\hline i & Parabolic trough collector field & 2 & HP-by-pass valve & 9 & Condenser \\
\hline ii & Fossil auxiliary heater & 3 & HP inlet valve & 10 & Condenser pump \\
\hline iii & Molten salt storage system & 4 & HP turbine & 11 & LP pre-heater \\
\hline iv & Solar field pump & 5 & LP-by-pass valve & 12 & Feed-water tank \\
\hline v & Expansion vessel & 6 & LP inlet valve & 13 & Feed-water pump \\
\hline vi & Power block by-pass & 7 & LP turbine & 14 & HP pre-heaters \\
\hline 1 & Steam generator compound & 8 & Generator & & \\
\hline
\end{tabular}

Figure 1. Hydraulic plant scheme

\section{Reference System}

For the modelling and simulation a parabolic trough power plant similar to the commercial systems in Spain was chosen. Figure 1 shows the hydraulic layout of the plant with all relevant components. Table 1 gives an overview of relevant thermodynamic parameters, as well as heat transfer fluid (HTF) and steel masses. In the same manner parameters of the power block are shown in Table 2. As already explained, the heat transfer fluid is heated up in the solar field and the heat is transferred through the steam generator (SG) to the power block (PB). There, electricity is produced in a conventional water-steam cycle. Heat can also be transferred to the thermal energy storage (TES) system via a heat exchanger. The sensible heat is stored in molten salt, which is pumped from the cold to the hot tank. The flow direction is reversed for discharge mode). During start-up, in case the thermal power must be limited, the power block by-pass is activated.

The steam generator consists of an economiser, evaporator, superheater and 2 reheaters, one for low and one for high temperature. There are two highpressure (HP) turbine stages and 5 low-pressure (LP) turbine stages. The power block is equipped with a regenerative feed-water system, where the feed-water tank is connected to the first bleed of the low pressure turbine and is situated between low-pressure preheaters and feed-water pump.

Table 1. Parameters of the solar circuit

\begin{tabular}{|l|l|}
\hline Parameter & Specification \\
\hline $\mathrm{HTF}$ & $\mathrm{VP} 1$, thermal oil \\
\hline Collector & Eurotrough \\
\hline Length of collector & $150 \mathrm{~m}$ \\
\hline Aperture Width of Collector & $5,77 \mathrm{~m}$ \\
\hline Total number of collectors & 576 \\
\hline Nominal SF mass flow, $\dot{m}^{\mathrm{SF}}$ & $1053 \mathrm{~kg} / \mathrm{s}$ \\
\hline $\begin{array}{l}\text { Nominal } \mathrm{SF} \text { temperature } \\
\text { (inlet/outlet), } T_{\text {in }}^{\mathrm{SF}}, T_{\text {out }}^{\mathrm{SF}}\end{array}$ & $293^{\circ} \mathrm{C} ; 393^{\circ} \mathrm{C}$ \\
\hline $\begin{array}{l}\text { Thermal power at } 837.5 \mathrm{~W} / \mathrm{m}^{2} \\
\text { (perpendicular irradiation) }\end{array}$ & $\sim 285 \mathrm{MW}$ \\
\hline TES capacity & $7 \mathrm{~h}$ \\
\hline total steel mass & $965 \mathrm{t}$ \\
\hline total HTF mass & $1390 \mathrm{t}$ \\
\hline
\end{tabular}


Both turbines are equipped with a by-pass valve and an inlet valve. In nominal operating mode the inlet valves are fully open and the by-pass valves are closed and the power block works in sliding pressure mode. During start-up procedure pressure and temperature gradients at the inlets of the turbines and in the steam generator are restricted. Furthermore, depending on the phase, live- and reheat steam mass flow is restricted. Live-steam and reheat mass flow are therefore controlled with the inlet valves. At the same time, livesteam and reheat steam pressure can be limited by opening the by-pass valves. In that manner steam is transferred to the condenser where it is finally condensed and heat is dissipated leading to a pressure reduction.

Table 2. Parameters of the power block

\begin{tabular}{|l|l|}
\hline Parameter & Specification \\
\hline Nominal gross electric power & $50 \mathrm{MW}$ \\
\hline nominal thermal power & $125 \mathrm{MW}$ \\
\hline nominal gross efficiency & $39.9 \%$ \\
\hline $\begin{array}{l}\text { nominal live-steam parameters } \\
p_{\mathrm{in}}^{\mathrm{HP}}, T_{\mathrm{in}}^{\mathrm{HP}}, \dot{m}_{\mathrm{in}}^{\mathrm{HP}}\end{array}$ & $\begin{array}{l}101 \mathrm{bar} ; 381{ }^{\circ} \mathrm{C} ; \\
53 \mathrm{~kg} / \mathrm{s}\end{array}$ \\
\hline $\begin{array}{l}\text { nominal steam parameters } \\
\text { re-heater, } p_{\text {in }}^{\mathrm{LP}}, T_{\text {in }}^{\mathrm{LP}}\end{array}$ & $\begin{array}{l}20 \mathrm{bar} ; 381{ }^{\circ} \mathrm{C} ; \\
45 \mathrm{~kg} / \mathrm{s}\end{array}$ \\
\hline No. of turbine stages & $2 \mathrm{HP}, 5 \mathrm{LP}$ \\
\hline Nominal operating Mode & sliding pressure \\
\hline SG volume water / steam & $70 \mathrm{~m}^{3}$ \\
\hline SG volume HTF & $115 \mathrm{~m}^{3}$ \\
\hline SG steel mass & $435 \mathrm{t}$ \\
\hline FWS volume water / steam & $80 \mathrm{~m}^{3}$ \\
\hline FWS steel mass & $50 \mathrm{t}$ \\
\hline
\end{tabular}

The split design of reheaters is not common in all commercial plants but the standard configuration of the Danish company Aalborg CSP, see (Aalborg CSP, 2015). Furthermore, unlike some other parabolic trough plants, that are equipped with tube-and-shell heat exchangers, Aalborg CSP only delivers headertype heat exchangers for this application. Aalborg's evaporator is realized as two separate evaporator vessels (with thermal oil in the internal piping and water in the external pass) and a steam drum connected with so-called risers and downcomers. The evaporator works with natural circulation. Aalborg CSP provided DLR with geometric and thermodynamic data of their steam generators. The data is confidential, but can be used for the simulation within the Turikon project.

The turbine configuration is similar to a commercial system of MAN Diesel \& Turbo. MAN provided DLR with parameters and data about restrictions during start-up procedure. There are 3 start-up procedures for cold, warm, and hot start-up. The start-up procedure depends on the temperature of the casings of the turbines and their inlet valves. Amongst other constraints the following temperatures of the casing of the HP inlet valve are prescribed:

- hot start-up: $\mathrm{t}>240{ }^{\circ} \mathrm{C}$

- warm start-up: $\mathrm{t}>180$

- cold start-up: $\mathrm{t}<180$

The temperature of the casing depends on the cooldown process and on the insulation of the turbine components. In the example in section 4 after 3:45 hours of cool-down time, a hot start-up can be carried out, while in the second example a cool down time of 12:45 hours entails a warm start-up. Since cold start-up represents a rather rare event, in the present simulation study only that case was not examined.

\section{Modelling}

\subsection{Solar Library of the DLR}

The solar field model was built up with components from the DLR solar library. In the field of line focus systems the first modelling work in DLR with Dymola was carried out in the framework of a thesis, see (Hirsch, 2005). A comprehensive dynamic library of solar field components, namely for direct steam generation systems, was developed, see (Hirsch et al, 2005). This library was later extended in order to use single-phase fluids as thermal oil and also molten salt, see (Hirsch et al, 2012). Due to the utilization of standard Dymola connectors, such as Modelica 3.x fluid connectors, the library can be combined with standard Modelica libraries.

\subsection{ThermoPower Library}

The power block of the plant model was built up with components from the freely available ThermoPower library which has been developed in the Politecnico di Milano since 2003, see (Casella et al, 2003; Casella et $a l, 2006)$. The library contains dynamic models of all relevant components of conventional water-steam, gas turbine, and combined cycle power plants. Power plants also including control system and grid connection can be build up and simulated with the library. Nowadays, the ThermoPower library also support fluid connectors of the Modelica 3.x standard, see (Casella, 2015) and can hence be coupled with other Modelica libraries. The newest Version of the ThermoPower Library is 3.1 Beta 0 , while for the herepresented simulations a preliminary version from 2013 was used.

In the standard version, the ThermoPower library does not support thermal oil as heat transfer fluid. Therefore, some additional components had to be developed for the here-presented plant model.

\subsection{Plant Model}

Figure 3 shows the first layer of the plant model in Dymola. The model is subdivided in submodels 


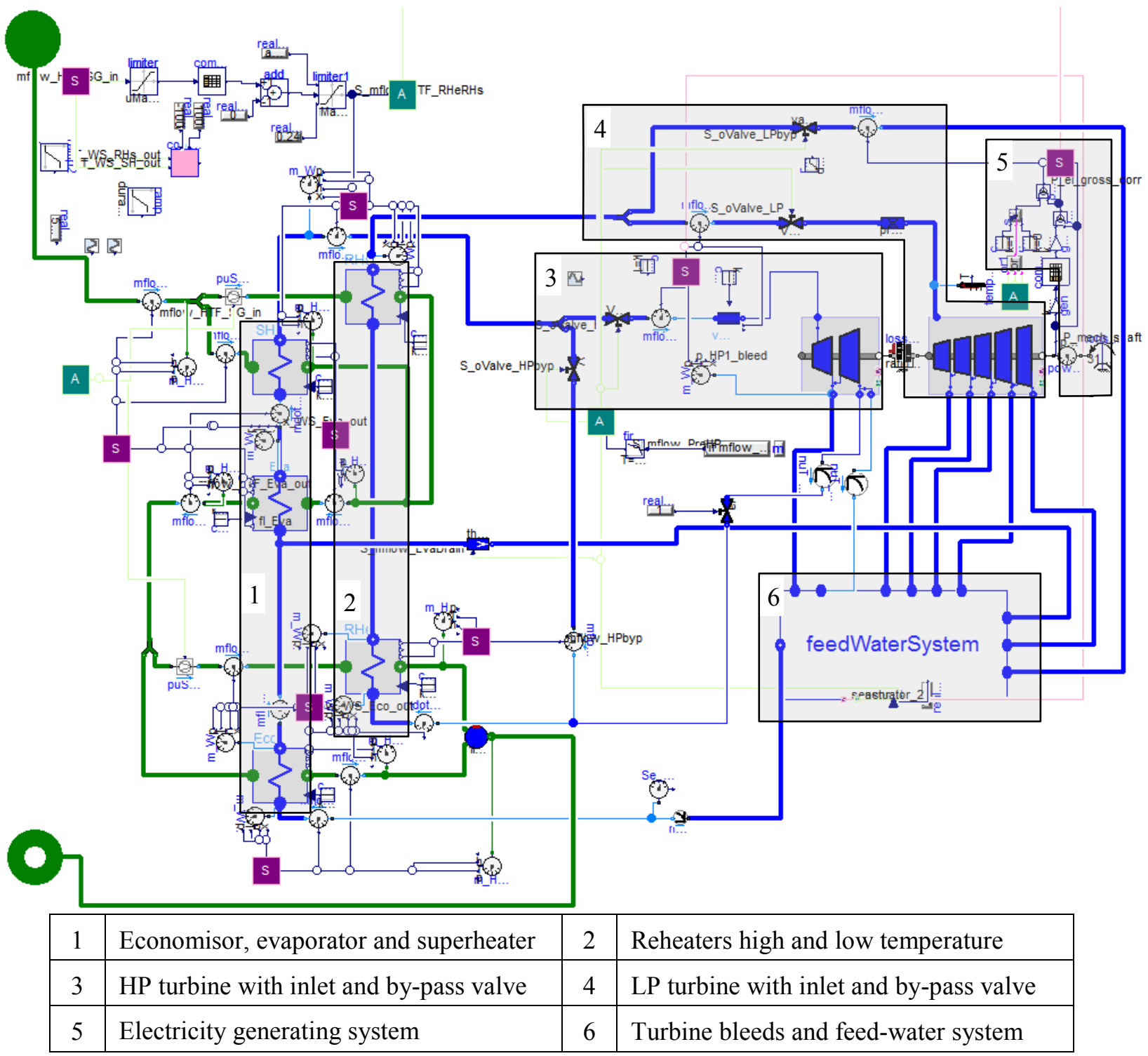

Figure 2. Model of the power block

representing the HTF circuit (solar field and storage system), the power block, and a separate control system for both. In the solar field and in the power block all major fluid and steel volumes are represented. The model comprises all components that are necessary for nominal operation and start-up procedure. In a real plant there is a multitude of additional pipes and valves, which are necessary for rare operating modes or maintenance, which are not accounted for in the model.

The pipes of the solar field are represented as oneaxis discretized pipe models. As published in (Hirsch et al, 2010) the solar field is represented by one collector loop and a representative header system. The steel and fluid masses correspond to the ones of the real solar field. For the sake of brevity, the model of the solar field is not described here in detail.

Heat exchangers of the power block are also built up with one-axis discretized pipes models. The power block model comprises turbines, valves, pumps, heat exchangers, and vessels. The presented reference system differs in some details from conventional water -steam power blocks. In most cases standard models from the ThermoPower library could be used with some adaptions for the modelling of the power block.

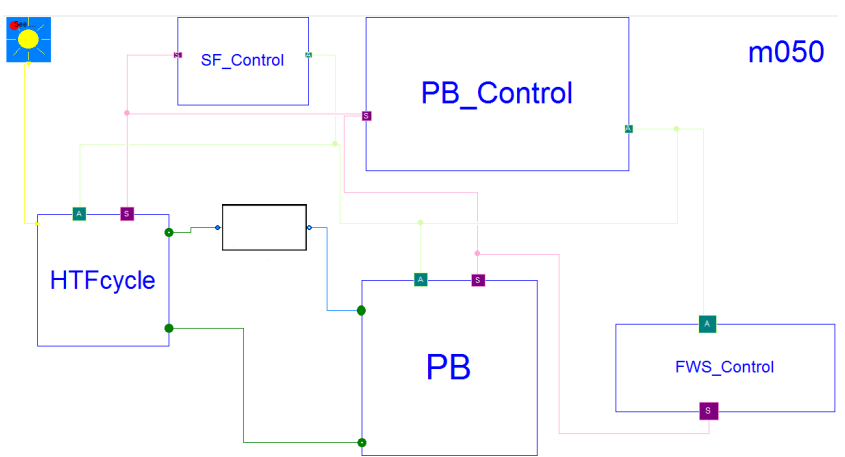

Figure 3. First layer of the plant model

In contrast to plant models in stationary simulation tools set point values cannot be prescribed. Therefore, 
a comprehensive control system had to be developed. This system controls for example:

- outlet temperature of the solar field

- fill-level of vessels, e. g. in evaporator and feed-water system

- live-steam pressure and mass flow during start-up

In the following paragraphs some examples of the plants submodels are shown.

\subsection{Model of the Power Block}

The model of the power block is shown in Figure 2. Blue lines represent the water / steam piping and green lines the HTF piping. The two models which are used for the steam generator are described in the following sections. High and low-pressure turbines, inlet and bypass valves are built up entirely with models from the ThermoPower library. The relation between pressure and mass flow is implemented with Stodola's law. Turbine casings and valve boxes are modelled as cylindrical steel masses.

The standard models from the ThermoPower library had to be adapted for the feed-water system. Every preheater and aftercooler, as well as feed-water tank are modelled. Only the fill-level of the pre-heaters are controlled. The bleed mass flows of the turbines adjust themselves depending on the heat exchange coefficients and the temperatures of the preheaters.

\subsubsection{Economisor, Superheater, and Reheater}

Figure 4 shows the model of a heat exchanger which is used for the economizer, the superheater, as well as the low and the high temperature part of the reheater.

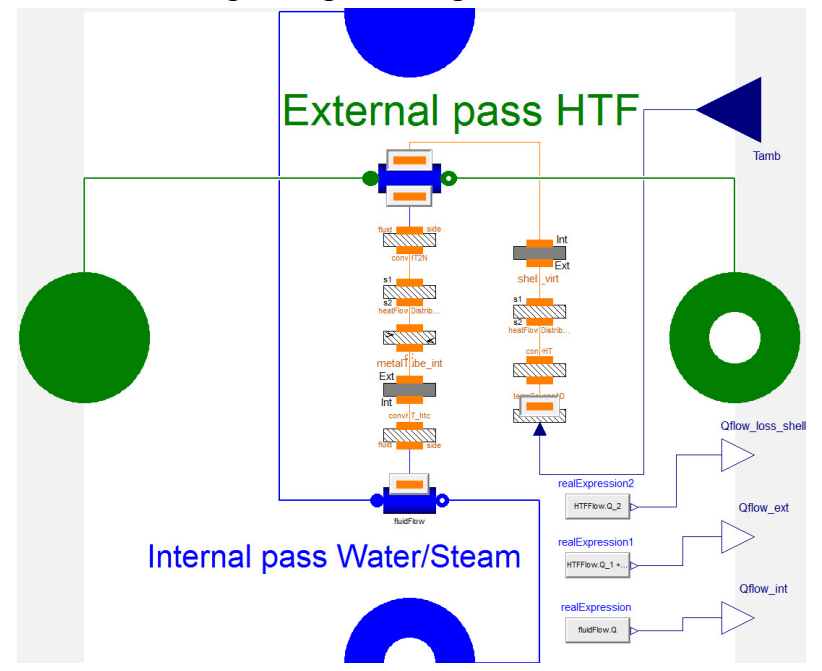

Figure 4. Model of economizer, superheater and reheater

The model is based on the heat exchanger models of the ThermoPower library, see for example (Casella et $a l, 2006)$. However, the flue gas on the external pass was replaced by thermal oil and the parameters had to be adapted. In the superheater and in the reheaters the internal pass is filled with steam and in the economizer there is liquid water. External and internal pass are modelled as a representative one-axis discretized circular flow and in between there is a cylindrical steel wall. The heat transfer between the two passes is counter current. In addition to the standard model of the ThermoPower library there is also a cylindrical steel wall representing the shell of the heat exchanger. A heat loss from the shell surface to the environment is implemented, as well. The complex 3-dimensional heat transfer and the flow geometry of the tube bundle of the real heat exchanger are not represented in detail.

However, the model is using the fluid and steel volumes, the throughput-time, and the load-dependent heat transfer coefficient of the real heat exchanger and represents therefore an adequate simplification.

\subsubsection{Model of the Evaporator}

Figure 5 shows the model of the evaporator. Different from the economizer superheater, and reheaters water and steam is in external pass while the thermal oil circulates trough the internal pass. The thermal oil flow is modelled as a circular flow. There is a cylindrical steel wall between internal and external pass representing the wall of the piping. The steam drum is modelled as a volume with steel wall that contains a water phase and a steam phase in equilibrium. As in the models of the previous section the complex 3-D geometry of the evaporator is not represented but fluid and steel volumes, and heat transfer coefficients match the ones of the real evaporator.

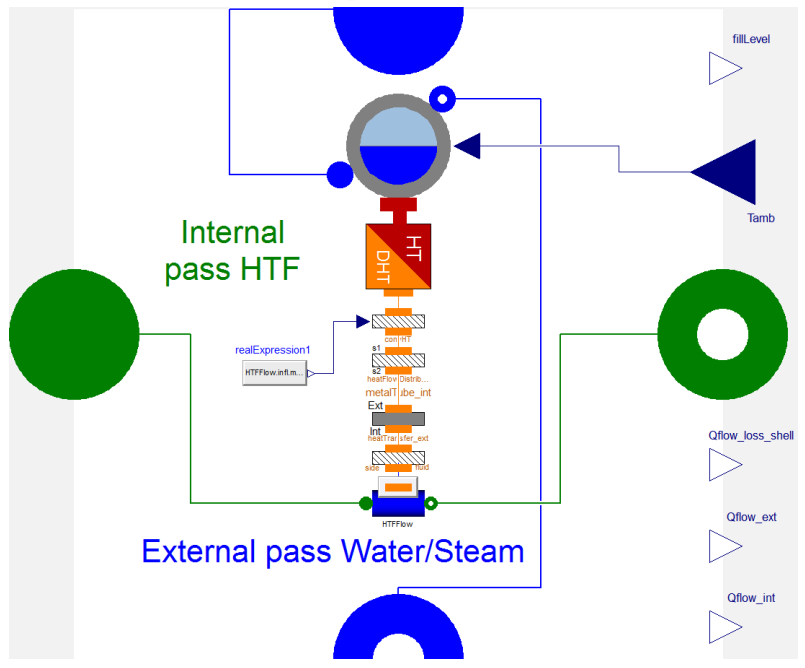

Figure 5. Model of evaporator

\section{Simulation of Load Changes}

A second plant model was built with the thermodynamic cycle tool Ebsilon Professional in order to derive parameters and to calibrate the Dymola model. Since Ebsilon Professional is well-respected tool in the field of steady-state analysis of thermal power plants, the here presented scenario serves as a validation for the Dymola power block model in stationary operating points. 
Figure 6 shows a step-wise simulation of part-load points from $50 \mathrm{MW}_{\mathrm{el}}$ to $10 \mathrm{MW}_{\mathrm{el}}$ with the Dymola model. The HTF mass flow through steam generator and hence the thermal power to the power block was adapted in order to adapt the electrical power. The adaption time of the mass flow is set to two minutes. In the same diagram the electrical power of the steadystate model is shown. With identical gross electrical power in stationary conditions, the corresponding thermal power delivered to the power block deviates between both models by less than $0.5 \%$ in full-load and less than $2 \%$ in part-load. The differences between both models are due to different model assumptions namely in the part-load calculation. Since the focus of the Dymola model is the simulation of transient behavior this deviation is considered as acceptable.

Due to its inertia the Dymola model needs a settling time, $t_{\text {sett }}$ to reach stationary conditions. As a criterion, the point in time is chosen when the electric power $P_{\text {el }}(t)$ differs by less than $1 \%$ from the final value $P_{\text {el,final }}$ :

$$
\left(\left|\frac{P_{\text {el,final }}-P_{\text {el }}(t)}{P_{\text {el,final }}}\right|\right)_{\left(t_{\text {sett }}+t_{\text {ramp }}\right)}<0.01
$$

Since, the ramp of the load change takes 2 minutes $t_{\text {ramp }}$ is deduced.

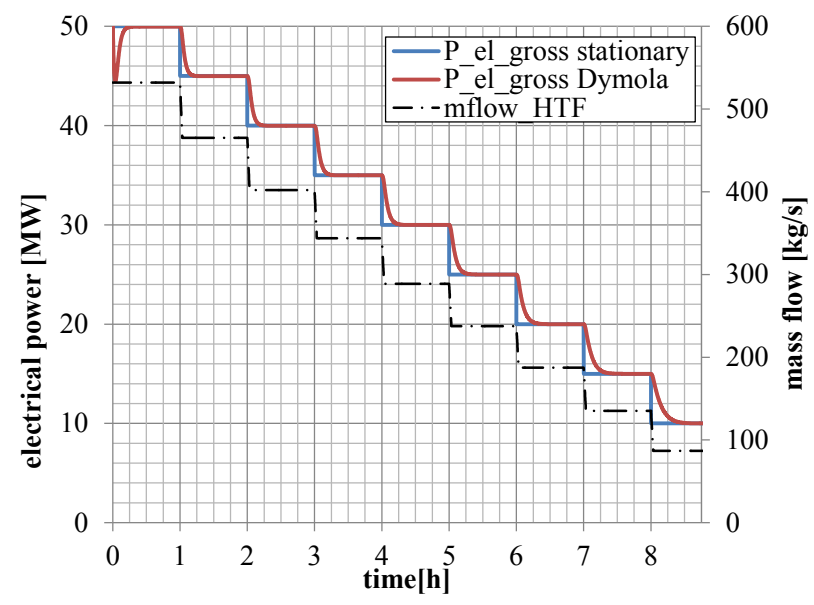

Figure 6. Electric power and mass flow

From Figure 6 it can be concluded that the settling time is load-dependent. Three examples are given:

- from 50 to $45 \mathrm{MW}, 6 \mathrm{~min}$

- from 35 to $30 \mathrm{MW} 9 \mathrm{~min}$

- from 15 to $10 \mathrm{MW}, 25 \mathrm{~min}$

The settling time is much longer, in part load operating points. The reason for that is that the heat stored or released from the fluid and steel masses is, compared to the totally transferred thermal power, much more important in part load than in full load.

\section{Start-up Simulation}

\subsection{Heat Balance and Start-up Losses}

A heat balance is established in this section in order to evaluate the energy consumption of the start-up procedure. For this purpose the thermodynamic state of the plant is introduced, see equ. (2). $Q_{\text {state }}$ represents the total heat in all fluid and steel masses in the system compared to a reference state. For water, usually, liquid state at $0{ }^{\circ} \mathrm{C}$ is taken as reference. However, the choice of reference state is arbitrary and not of importance since in the present paper only the difference between two states is calculated.

$$
\begin{aligned}
Q_{\text {state }}= & \sum_{1}^{i}\left(u_{\mathrm{f}, i}\left(T_{i}, p_{i}, x_{i}\right) * m_{\mathrm{f}, i}\right) \\
& +\sum_{1}^{j}\left(c_{\mathrm{s}, j}\left(T_{j}-T_{\mathrm{ref}}\right) * m_{\mathrm{s}, j}\right)
\end{aligned}
$$

with:

$T, p, x \quad$ temperature, pressure and steam quality

$T_{\text {ref }} \quad$ reference temperature

$m_{\mathrm{f}}, m_{\mathrm{s}} \quad$ fluid and steel mass

$u_{\mathrm{f}} \quad$ specific internal energy of fluid

$c_{\mathrm{S}} \quad$ specific heat capacity of steel

After shut-down the plant cools down and this heat must be compensated during start-up. The theoretical energy for the heat-up phase, index HU, of the Solar field, index SF, of all thermal masses between cold state, at point in time $t_{0}$, and the hot state, at $t_{1}$, writes:

$$
Q_{\mathrm{HU}}^{\mathrm{SF}}=Q_{\mathrm{state}}^{\mathrm{SF}}\left(t_{1}\right)-Q_{\mathrm{state}}^{\mathrm{SF}}\left(t_{0}\right)
$$

For the power block accordingly:

$$
Q_{\mathrm{HU}}^{\mathrm{PB}}=Q_{\text {state }}^{\mathrm{PB}}\left(t_{1}\right)-Q_{\mathrm{state}}^{\mathrm{PB}}\left(t_{0}\right)
$$

The heat-up energy also represents the minimal thermal energy need for a start-up procedure in case no other heat losses occur. However, during the start-up procedure of the solar field, heat losses of headers and piping occur, index 1,HP. Furthermore, the solar field must partly be defocused, index 1,def, in some cases in order to avoid overheat of collectors. Hence, the total start-up energy, of the solar field including these losses writes:

$$
Q_{\mathrm{SU}}^{\mathrm{SF}}=Q_{\mathrm{HU}}^{\mathrm{SF}}+Q_{\mathrm{l}, \mathrm{def}}+Q_{\mathrm{l}, \mathrm{HP}}
$$

During the power block start-up heat is dissipated when the turbine by-passes are open, as already described in section 2 . The power block start-up energy hence is the sum of the heat-up energy and the energy that is lost due to by-pass operation, index 1,byp: 


$$
Q_{\mathrm{SU}}^{\mathrm{PB}}=Q_{\mathrm{HU}}^{\mathrm{PB}}+Q_{1, \mathrm{byp}}
$$

The total energy for plant start-up then writes:

$$
Q_{\mathrm{SU}}=Q_{\mathrm{SU}}^{\mathrm{PB}}+Q_{\mathrm{SU}}^{\mathrm{SF}}
$$

As defined in (Hirsch et al, 2012) the relation between the minimal start-up consumption (equals the heat-up energy) and the start-up consumption of the real process writes

$$
\psi=\frac{Q_{\mathrm{SU}}}{Q_{\mathrm{HU}}}
$$

$\psi$ is always greater than 1 and can be used to parameterize simplified models for annual electrical yield analysis calculation.

\subsection{Test Scenario}

A scenario was chosen in which daily operation, cooldown phase, and start-up procedures can be tested. The scenario comprises two consecutive days, which are generated with a clear-sky model for a typical Spanish site for the $21^{\text {st }}$ of March. The simulation results are shown in Figure 7. The upper diagram shows the direct normal irradiation (DNI) in $\mathrm{W} / \mathrm{m}^{2}$, as well as the effective DNI, which is corrected by all angle losses. Typical for a north-south aligned parabolic trough plant, the effective DNI peaks in the morning and in the evening. The diagram in the middle shows the solar field temperatures and mass flows, index SF, and the thermal oil mass flow to the steam generator, index SG. Due to model limitations the mass flow of the solar field cannot be zero. Therefore, even in the night the solar field is in recirculation mode. Since, the influence of the mass flow on heat losses is marginal this simplification does not affect the energy balance of
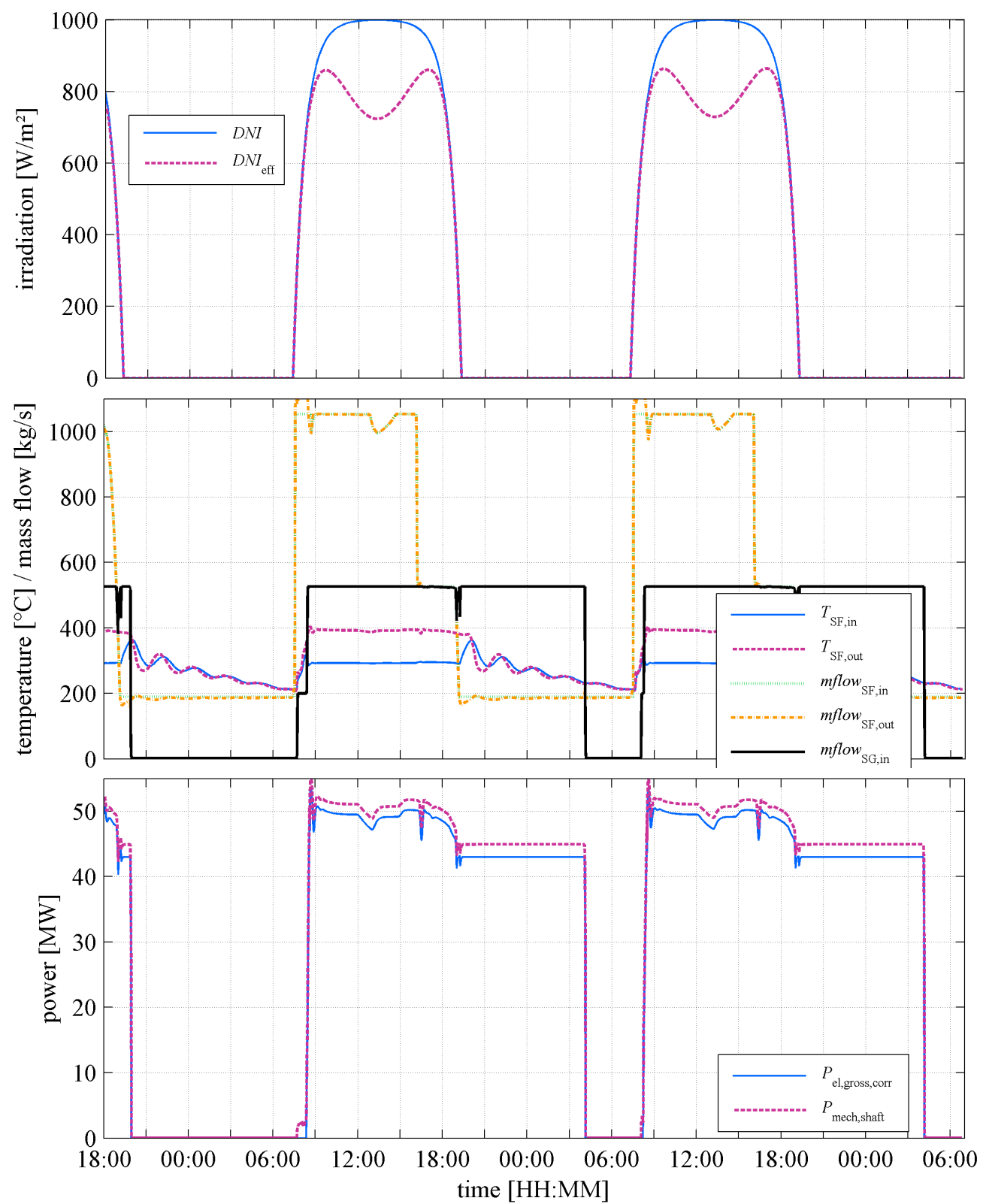

Figure 7. Plant Operation during two clear-sky days 
the cool-down procedure. The lower diagram shows the mechanical shaft power of the turbine and the gross electrical power which includes the efficiency of the generator. The plant operates in a purely solar driven mode. That means that electricity shall be produced as long as possible. Load scheduling is not foreseen.

The scenario begins in the first evening with an empty storage system. The extended cool-down phase in the first night leads to a warm turbine start-up procedure during the first morning. During the first operating day, the solar field mass flow drops around 16:00 since the storage system is fully charged. In the evening after sunset, the plant is operated from storage until shortly after 4:00. During storage discharge operation, the temperature of the thermal oil is considerably lower due to the temperature difference of the heat exchanger. This leads to lower live-steam temperatures and to a reduced electrical power. The short cool-down phase of the power block entails a hot start-up procedure in the morning of the second day.

\subsection{Detail Start-Up Procedure}

Warm and hot start-procedures are shown in Figure 8. On the left and on the right the upper diagrams show temperatures and pressures in the water steam-cycle at the outlet of the superheater (SH), reheater superheater part (RHs), as well as the temperatures of the casing of the high-pressure turbine (VaHP) and the thermal oil at the steam generator inlet (SG).

The diagrams below show the gross electrical power relative to $50 \mathrm{MW}$ in $\%$, as well as the steam mass flows at the inlet and the by-pass valve of the low pressure turbine (LP, LPbyp) and the high pressure turbine (HP, HPbyp). As indicated as well in Figure 8, the start-up procedure is subdivided into phases A, B, $\mathrm{C}$, which are between shut-down and nominal mode of the power block. For further information about the phases see Table 3. As soon as the irradiation conditions allow, the solar field is heated-up in recirculation mode. When the temperature is high enough, a part of the recirculation mass flow is deviated through the steam generator. This mass flow is called $\dot{m}_{\mathrm{SFtoPB}}$ (compare with Figure 1) and is set to $300 \mathrm{~kg} / \mathrm{s}$ in this section. During start-up, the live- and reheat steam mass flows are controlled with the HP and LP inlet valves. The pressure is controlled, with the bypass valves. The constraints for pressure and temperature are prescribed by the manufacturers of steam generator and turbine and are confidential. In principle in the hot and in the warm start-up procedure there are the same phases and the same constraints, however with different values.

The purpose of phase $A$ is to preheat the casings of HP and LP turbine and to reach minimal live and reheat steam conditions. In that phase the mass flow is very small. In phase B the turbine is turned and synchronized, also with a small mass flow. The purpose of phase $\mathrm{C}$ is to increase the electrical power by opening turbine inlet valves and closing the by-pass valves. During that phase gradients for mass flow, temperature, pressure, and electrical power must kept below a certain value. At the end of the phase, the power block is in nominal mode with sliding pressure.

Table 3. Phases of the start-up procedure

\begin{tabular}{|l|l|l|}
\hline A & pre-heat & $\begin{array}{l}\text { Task: preheat of turbine (valve) casing } \\
\text { Limits: steam pressure and mass flows }\end{array}$ \\
\hline B & $\begin{array}{l}\text { Synchro- } \\
\text { nization }\end{array}$ & $\begin{array}{l}\text { Task: start-up and synchro of turbines } \\
\text { Limits: steam pressure and mass flows }\end{array}$ \\
\hline C & $\begin{array}{l}\text { charge } \\
\text { increase }\end{array}$ & $\begin{array}{l}\text { Task: increase of electr. production } \\
\text { Limits: Gradients of electrical power, } \\
\text { pressure and temperature }\end{array}$ \\
\hline
\end{tabular}

The zero point of the $\mathrm{x}$-axes in Figure 8 is defined as the beginning of the synchronization phase (B). During warm start-up procedure, left diagrams, phase $\mathrm{B}$ begins at $8: 15$ in morning of the first day. The preheat phase begins at 7:42 (not visible on the diagram) and phase $\mathrm{C}$ ends at 8:37. In the hot start-up procedure Phase $\mathrm{B}$ begins at 8:06 (zero point on of the x-axis). The preceding phase A takes only 1 minute since the valve boxes are already at a high temperature and the minimal live- and reheat steam conditions are attained quickly. The start-up procedure is terminated at 8:31.

The upper diagrams (Figure 8) show the ramp up of superheater and reheater temperatures and the livesteam pressure. It becomes visible, that the live- and reheat steam pressure are limited during phases $\mathrm{A}$ and $\mathrm{B}$ and are increased in phase $\mathrm{C}$ during the transition to the nominal operating mode. The lower diagrams (Figure 8) show the limitation of the steam mass flows during phase A and B, as well as the ramp-up in phase C. The ramp-up of the electrical power is in phase with the steam mass flows. Furthermore, the diagrams also show the by-pass mass flows which are due to the pressure control of the bypass valves. It becomes visible, that during the warm start-up procedure, more steam is condensed than in the hot start-up. The bypass steam is finally condensed. Therefore, thermal energy is dissipated which represents an energy loss.

The balance equations of section 5.1 are used in the following to establish an energetic evaluation of the start-up procedure, see Table 4. The total heat-up energy of power block and solar field, $Q_{\mathrm{HU}}$ sums up to 133.2 $\mathrm{MWh}_{\text {th }}$ and the total start-up energy, $Q_{\mathrm{SU}}$ to 180.7 $\mathrm{MWh}_{\text {th }}$ during the warm start-up. This represents almost 1.5 power block full load hours (equivalent to $125 \mathrm{MWh}_{\mathrm{th}}$ ). The difference between heat-up and startup energy, $Q_{1, \mathrm{SU}}=47.5 \mathrm{MWh}_{\text {th }}$ is $38 \%$ of the energy demand for a full-load-hour and also represents the maximal optimization potential for the start-up procedure. During the hot start-up the solar field heatup energy almost equals to the one of the warm start- 


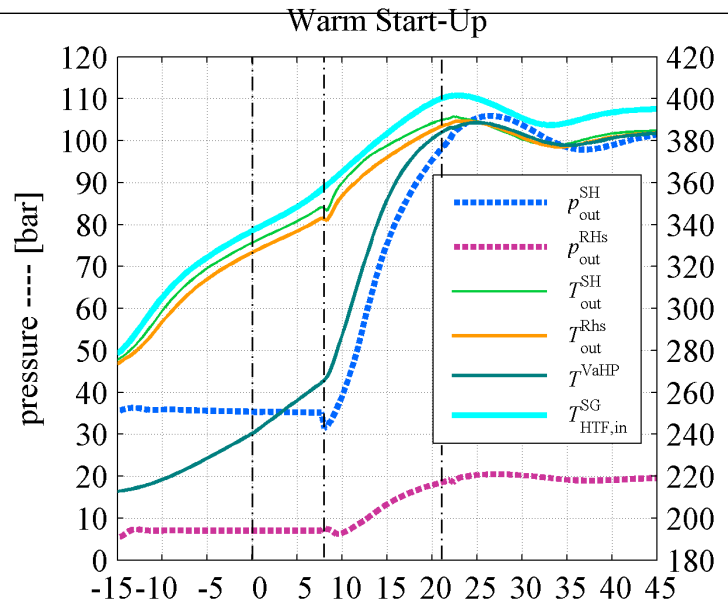

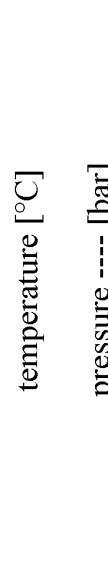
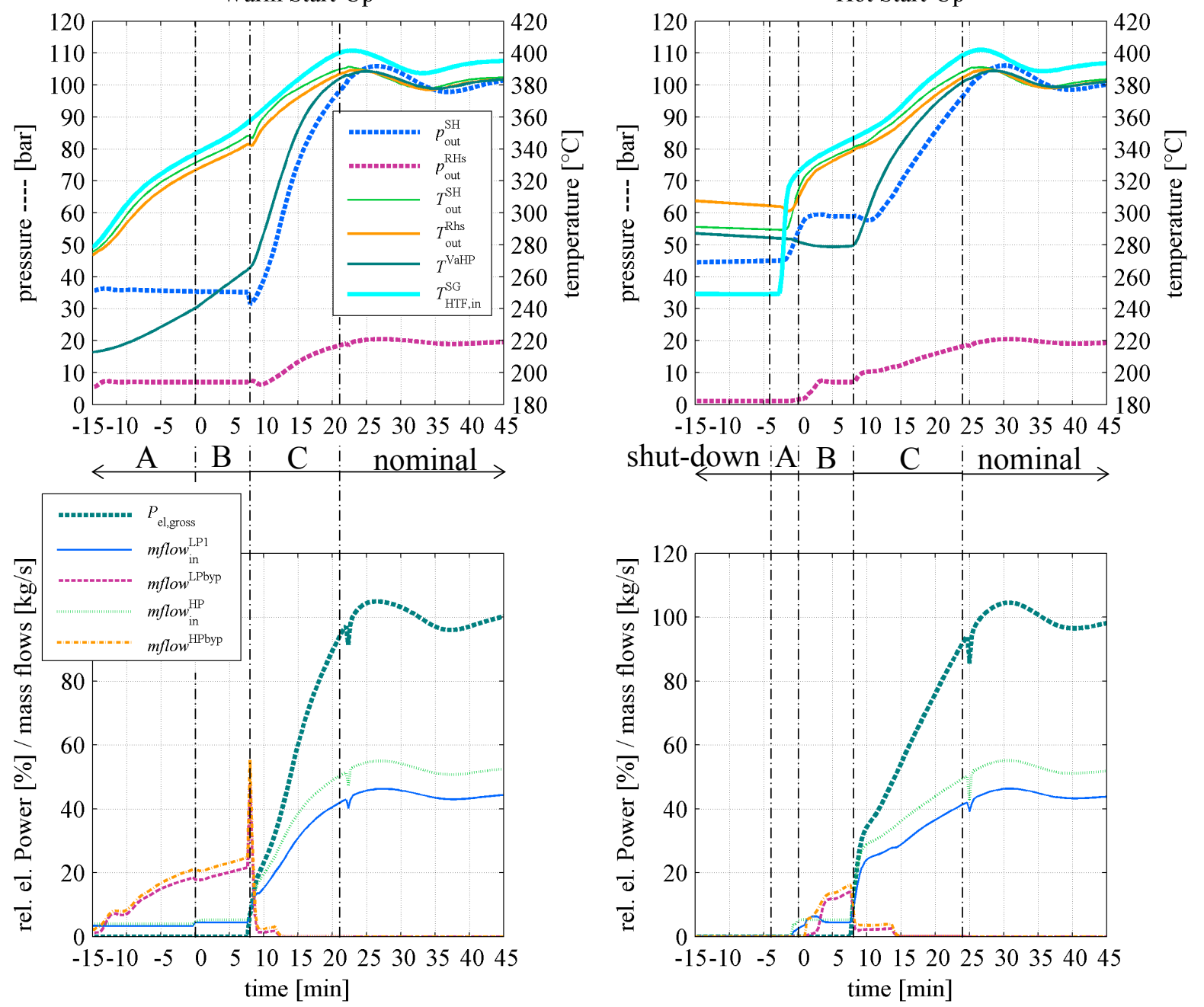

Figure 8. Warm and hot start-up. Phases: A preheat, B Synchronization, C load increase

up procedure, since the cool-down period of the solar field is similar. However, the power block start-up demands less energy due to the shorter stand-still time. In total $Q_{\mathrm{HU}}$ is $126.6 \mathrm{MWh}$ and $Q_{\mathrm{SU}} 154.7 \mathrm{MWh}$. Therefore, the optimization potential, $Q_{1, S U}$ is $28.1 \mathrm{MWh}$ representing $23 \%$ of the energy demand for a full-load-hour. The start-up factor for the warm startup is 1.35 and 1.22 for the hot start-up

Table 4. Energy Balance of the start-up

\begin{tabular}{|l|c|c|}
\hline & Warm start-up & Hot start-up \\
\hline$t_{\text {stand-still }}[\mathrm{h}]$ & $11: 45 \mathrm{~h}$ & $3: 55 \mathrm{~h}$ \\
\hline$Q_{\mathrm{HU}}^{\mathrm{SF}}[\mathrm{MWh}]$ & 114.2 & 114,0 \\
\hline$Q_{\mathrm{HU}}^{\mathrm{PB}}[\mathrm{MWh}]$ & 19.0 & 12.6 \\
\hline$Q_{\mathrm{SU}}^{\mathrm{SF}}[\mathrm{MWh}]$ & 135.8 & 134.0 \\
\hline$Q_{\mathrm{SU}}^{\mathrm{PB}}[\mathrm{MWh}]$ & 44.9 & 20.7 \\
\hline$Q_{\mathrm{l}, \mathrm{SU}}[\mathrm{MWh}]$ & 47.4 & 28.1 \\
\hline$\Psi \quad[-]$ & $\frac{180.7}{133.2}=1.35$ & $\frac{154.7}{126.6}=1.22$ \\
\hline
\end{tabular}

\subsection{Optimization of the start-up procedure}

The previous section has shown possible reduction potential of energy losses during start-up. On the one hand, the surplus power that is delivered from solar field to power block is dissipated due to by-passing. On the other hand, when the solar field reaches nominal operating state before the power block, losses occur due to defocusing, since also the charge power of the storage system is also limited. An minimum is supposed to be reached when power block and solar field reach nominal operating state at the same time. The thermal oil mass flow through the steam generator $\dot{m}_{\text {SFtoPB }}$, which controls the thermal power transferred to the power block was set to $300 \mathrm{~kg} / \mathrm{s}$ in the scenario of the previous section. This mass flow is now varied in order to find energetic optimum. Figure 9 shows the evolution of the losses and their sum $Q_{\mathrm{l}, \mathrm{Su}}$ for $\dot{m}_{\mathrm{SFtoPB}}$ from $50 \mathrm{~kg} / \mathrm{s}$ to $350 \mathrm{~kg} / \mathrm{s}$. As expected, with an increasing $\dot{m}_{\text {SFtoPB }}$ more heat is delivered to the power block and more heat must be dissipated and therefore $Q_{1, \text { byp }}$ increases. At the same time more heat is drawn from the solar field, and the need to defocus, hence $Q_{1, \text { def }}$, decreases. The heat losses of the solar field piping and equipment, $Q_{\mathrm{l}, \mathrm{def}}$, remain almost unaffected, since they are only temperature-dependent. The minimal value of $36.7 \mathrm{MWh}_{\mathrm{th}}$ for $Q_{\mathrm{l}, \mathrm{SU}}$ is attained with $\dot{m}_{\mathrm{SFtoPB}}=100 \mathrm{~kg} / \mathrm{s}-$ compared to $47.5 \mathrm{MWh}_{\text {th }}$ at 300 $\mathrm{kg} / \mathrm{s}$. The same variation was carried out for the hot 
start-up procedure, which leads to a very flat optimum. Since the optimization potential of $Q_{1, S U}$ is almost negligible, the results are not shown here.

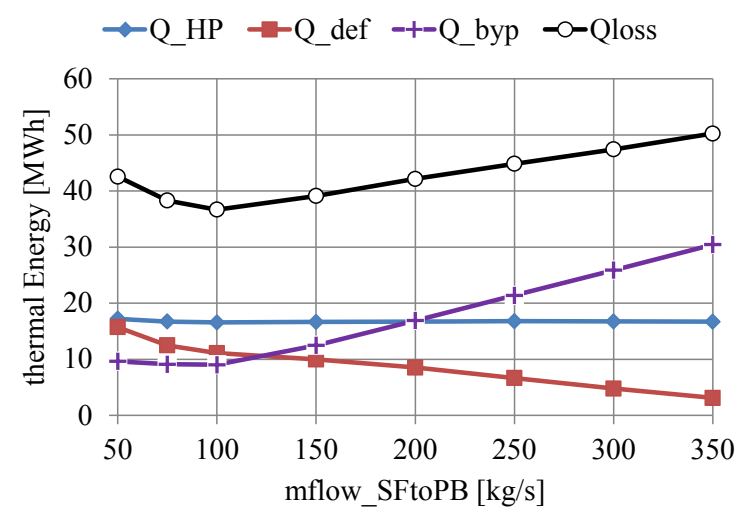

Figure 9. Energetic Start-up consumption over mass flow during warm start-up procedure

\section{Conclusions and Outlook}

A model of a parabolic trough power plant with thermal oil was developed with the DLR solar library and the publically available ThermoPower Library. The main focus of the modelling was put on the transient behavior, namely the start-up procedure, of the power block. With the model, the interaction between solar field, storage system and power block during start-up and the impact of transient effects is examined.

In a first step, the dynamic behavior of the power block during nominal operation with load changes is examined. As expected the thermal masses lead to a delayed behavior of the electricity production.

In a second step a scenario of two consecutive clearsky days was chosen for a simulation. During the first night an empty storage system entails a cool-down time of almost 12 hours which is followed by a warm startup procedure in the next morning. The totally consumed energy of the start-up procedure is 180.7 $\mathrm{MWh}_{\text {th. }} 133.2 \mathrm{MWh}_{\text {th }}$ are necessary for the heat-up of the thermal masses and $47.5 \mathrm{MWh}_{\text {th }}$ represent additional thermal mainly due to defocusing and bypassing. In the second night, a fully charged storage system leads to a hot start-up after a cool-down time of less than 4 hours. The energy consumption is 154.7 $\mathrm{MWh}_{\text {th }}$. In both cases the heat demand for the thermal masses of the solar field is the same, since the solar field cool-down time is equal in both cases.

In a last step, the thermal oil mass flow to the power block and hence the thermal power input during the start-up procedure was varied, leading to a reduction of around $11 \mathrm{MWh}_{\mathrm{th}}$ for the warm start-up procedure.

Finally, the paper shows the potential of the dynamic plant model in Dymola. With further simulations the impact of the inertial behavior of the power block could be evaluated with regards to dispatchability. Additional start-up simulations with modified plant configurations could provide more data on start-up consumption, for example as a function of plant size, cool-down time and irradiation conditions. Furthermore, new control strategies during start-up can be tested.

\section{Acknowledgements}

The authors would like to thank the German Federal State of North Rhine-Westphalia and the European Regional Development Fund for the financial support of the project TURIKON in the frame of the program progress NRW and the goal 2-program 2007-2013, Phase VI (Grant No. 64.65.69-EN-2019).

The authors would also like to thank Aalborg CSP for providing comprehensive data of their steam generators and Politecnico di Milano for making available the ThermoPower library.

\section{References}

Aalborg CSP. Aaalborg CSP steam plant configuration, 2015/04/16, www.aalborgcsp.com.

Francesco Casella and Francesco Schiavo. Modelling and Simulation of Heat Exchangers in Modelica with Finite Element Methods, 3rd International Modelica Conference, pp. 343-352, 2003.

Francesco Casella and Francesco Pretolani. Fast Start-up of a Combined-Cycle Power Plant - a Simulation Study with Modelica.pdf, 5th International Modelica Conference, pp. 7, 2006

Francesco Casella. ThermoPower - Open library for thermal power plant simulation, 2015/04/17, http://thermopower.sourceforge.net/.

Tobias Hirsch. Fortschritt-Berichte Energietechnik, Reihe 6, No. 535, VDI Verlag, Dynamische Systemsimulation und Auslegung des Abscheidesystems für die solare Direktverdampfung in Parabolrinnenkollektoren, 2005, ISBN: 3-18-353506-8.

Tobias Hirsch, Markus Eck, Wolf-Dieter Steinmann. Simulation of transient two-phase flow in parabolic trough collectors using Modelica, 4th International Modelica Conference, Vol. 1, pp. 403-412, 2005.

Tobias Hirsch and Markus Eck. Simulation of the Start-Up Procedure of a Parabolic Trough Collector Field with Direct Solar Steam Generation, 5th International Modelica Conference, pp. 135-143, 2006.

Tobias Hirsch, Heiko Schenk, Norbert Schmidt, Richard Meyer. Dynamics of Oil-based parabolic Trough Plants Impact of transient Behaviour on Energy Yields, 16th SolarPACES Conference, pp. 8, 2010.

Tobias Hirsch, Jan Fabian Feldhoff, Heiko Schenk. Start-Up Modeling for Annual CSP Yield Calculations, Journal of Solar Energy Engineering, 134 (3), pp. 031004-1..9, 2012, DOI: $10.1115 / 1.4006268$.

Protermo Solar. Protermo Solar - Asociación Española de la Industria Solar Termoeléctrica, 2015/04/16, http://www.protermosolar.com. 